\section{Nonsense-mediated mRNA decay maintains translational fidelity by limiting magnesium uptake}

\author{
Marcus J.O. Johansson ${ }^{1,2}$ and Allan Jacobson ${ }^{1,3}$ \\ ${ }^{1}$ Department of Molecular Genetics and Microbiology, \\ University of Massachusetts Medical School, Worcester, \\ Massachusetts 01655, USA; ${ }^{2}$ Department of Molecular Biology, \\ Umeå University, 90187 Umeå, Sweden
}

Inactivation of the yeast nonsense-mediated mRNA decay (NMD) pathway stabilizes nonsense mRNAs and promotes readthrough of premature translation termination codons. Although the latter phenotype is thought to reflect a direct role of NMD factors in translation termination, its mechanism is unknown. Here we show that the reduced termination efficiency of NMD-deficient cells is attributable to increased expression of the magnesium transporter Alr1p and the resulting effects of elevated $\mathrm{Mg}^{2+}$ levels on termination fidelity. Alr1p levels increase because an upstream ORF in ALR1 mRNA targets the transcript for NMD. Our results demonstrate that NMD, at least in yeast, controls $\mathrm{Mg}^{2+}$ homeostasis and, consequently, translational fidelity.

Supplemental material is available at http://www.genesdev.org.

Received March 26, 2010; revised version accepted May 24, 2010.

Eukaryotic quality control mechanisms detect and degrade aberrant RNAs that arise from genomic mutations or mistakes in transcription and RNA processing. One such mechanism, nonsense-mediated mRNA decay (NMD), targets mRNAs containing premature translation termination codons for rapid degradation, thus ensuring that protein-encoding transcripts encompass proper ORFs (Jacobson and Izaurralde 2007). The destabilization of nonsense-containing transcripts requires their translation and a distinct set of trans-acting factors, including the conserved Upf1, Nmd2 (Upf2), and Upf3 proteins (Jacobson and Izaurralde 2007). Yeast strains with mutations in the UPF1, NMD2, or UPF3 genes show not only elevated nonsense mRNA levels, but also increased translational readthrough of premature stop codons (Weng et al. 1996; Maderazo et al. 2000; Wang et al. 2001; Keeling et al. 2004). This effect is sufficient to promote nonsense suppression, and has been thought to reflect a direct function of the Upf/Nmd proteins in translation termination, possibly as a consequence of their interactions with the release factors eRF1 and eRF3 (Czaplinski et al. 1998; Maderazo et al. 2000;

[Keywords: NMD; translation termination; magnesium uptake; uORF] ${ }^{3}$ Corresponding author.

E-MAIL allan.jacobson@umassmed.edu; FAX (508) 856-5920.

Article is online at http://www.genesdev.org/cgi/doi/10.1101/gad.1930710.
Wang et al. 2001). However, the mechanism by which the Upf/Nmd proteins enhance the efficiency of translation termination is largely unknown. To elucidate the role of NMD factors in translation termination, we screened for mutations that counteract the nonsense suppression phenotype of NMD-deficient cells, and characterized in detail the principal complementation group of the resulting anti-suppressors.

\section{Results and Discussion}

Mutations in the ALR1 gene counteract the nonsense suppression phenotype of NMD-deficient cells

The screen for anti-suppressors was initiated by using Saccharomyces cerevisiae upf1 mutants harboring can1100 (UAA) and leu2-2 (UGA) nonsense alleles. The lack of NMD in these cells leads to stabilization of the can1-100 and leu2-2 mRNAs and readthrough of their premature stop codons (Weng et al. 1996; Maderazo et al. 2000; Wang et al. 2001), generating functional, full-length Can1p and Leu2p. The production of Can $1 p$ and Leu2p can be scored as sensitivity to the toxic arginine analog canavanine and growth on medium lacking leucine, respectively. By selecting for upf1 cells resistant to canavanine (Can ${ }^{\mathrm{R}}$ ) and subsequently screening for the inability to grow on medium lacking leucine $\left(\mathrm{Leu}^{-}\right)$, strains harboring mutations that reduced upf1-induced nonsense suppression were identified. One complementation group defined strains with mutations in the $A L R 1$ gene, which codes for a plasma membrane protein required for efficient magnesium uptake (MacDiarmid and Gardner 1998; Graschopf et al. 2001). To demonstrate unambiguously that a mutation in the $A L R 1$ gene generates anti-suppression, we combined an alr1s allele with a upf1 $1 \Delta$ mutation.

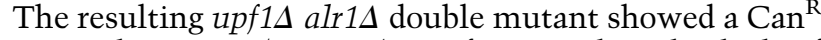
$\mathrm{Leu}^{-}$phenotype (Fig. 1A), confirming that the lack of Alrlp counteracts the nonsense suppression phenotype of upf1 cells. Furthermore, the alr1s allele also counteracted nonsense suppression in cells deleted for NMD2 or UPF3 (Fig. 1A), indicating that the underlying mechanism is relevant for NMD-deficient cells in general.

\section{The fidelity of translation termination is enhanced by the lack of Alr1p}

The lack of nonsense suppression in upf1 alr1 double mutants could be caused by either a reduction in leu2-2 and can1-100 mRNA levels or improved termination efficiency. The former possibility was excluded by the finding that the levels of 1eu2-2 and can1-100 mRNAs were in fact higher in upf1s alr1s cells than in upf1s cells (Fig. 1B; Supplemental Table S1). To assess directly whether a lack of Alrlp improves termination efficiency, we used a dual-luciferase readthrough reporter system (Keeling et al. 2004) that controls for differences in mRNA abundance and efficiency of translation initiation. The level of readthrough was quantified by determining the ratio of firefly and Renilla luciferase activities in a strain harboring a construct in which the respective luciferase genes are separated by a stop codon, and comparing the ratio to that obtained with a construct in which a sense codon replaced the stop codon (Keeling 

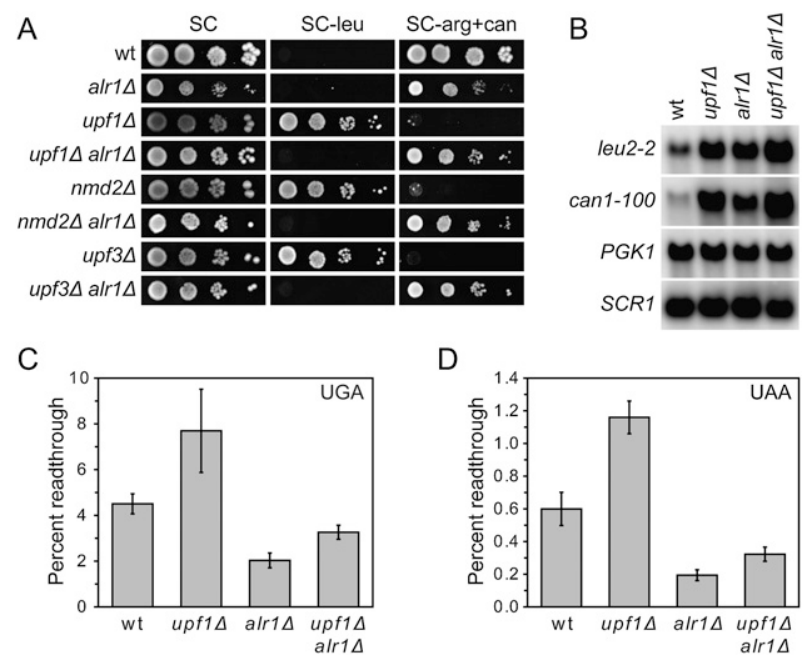

Figure 1. A mutation in the ALR1 gene counteracts the termination defect of NMD-deficient cells. (A) Nonsense suppression in NMD- and Alrlp-deficient cells. The indicated strains (MJY142, MJY67, MJY130, MJY447, MJY169, MJY193, MJY150, and MJY151) were grown overnight in liquid synthetic complete $(\mathrm{SC})$ medium at $30^{\circ} \mathrm{C}$. Cells were serially diluted; spotted onto SC, SC-leu, and SC$\arg +\operatorname{can}(200 \mu \mathrm{g} / \mathrm{mL}$ can $)$ plates; and incubated for $3 \mathrm{~d}$ at $30^{\circ} \mathrm{C}$. $(B)$ Northern analysis of total RNA isolated from wild-type (MJY142), upf1s (MJY67), alr1s (MJY130), and upf1s alr1s (MJY447) cells grown in SC medium at $30^{\circ} \mathrm{C}$. The blot was probed for leu2-2, can1100, PGK1, and SCR1 transcripts using randomly labeled DNA fragments. The noncoding SCR1 transcript serves as a loading control. $(C, D)$ Readthrough levels of UGA $(C)$ and UAA $(D)$ stop codons in the wild-type (MJY142), upf1s (MJY67), alr1s (MJY130), and upf1s alr1s (MJY447) strains. The values represent the average of five independent experiments. The standard deviation is indicated.

et al. 2004). Analyses of UGA and UAA readthrough demonstrated that the alr1s allele counteracted the termination defect of upf1s cells (Fig. 1C,D). The alr1s allele also generated a reduction in readthrough in NMDproficient cells, implying that the lack of Alrlp leads to a general enhancement of termination fidelity. Importantly, growth on medium containing guanidine hydrochloride (Tuite et al. 1981) did not eliminate the effect of the alr1s allele, excluding the possibility that lack of Alr $1 p$ reduces readthrough by modulating the prion form of eRF3 $\left[\mathrm{PSI}^{+}\right]$or some other element cured by guanidine hydrochloride treatment (Supplemental Material; Supplemental Fig. S1).

\section{NMD-deficient cells show elevated Alr1p and Alr2p levels}

It is well established that the fidelity of in vitro translation systems is influenced by $\mathrm{Mg}^{2+}$ concentration; i.e., the levels of misreading at sense codons and readthrough at nonsense codons increases with increasing $\mathrm{Mg}^{2+}$ concentrations (Szer and Ochoa 1964; Capecchi 1967; Schlanger and Friedman 1973). Since a strain deleted for ALR1 shows reduced intracellular magnesium (Graschopf et al. 2001), and there is no evidence to suggest a direct role for Alr1p in translation termination, it seemed possible that the alr1s anti-suppressor effect could simply reflect reduced $\mathrm{Mg}^{2+}$ without explaining the mechanism by which NMD factors prevent translational readthrough. However, our earlier genome-wide approaches (He et al. 2003; Johansson et al. 2007) have shown that Upf1p associates with the ALR1 mRNA, and that this transcript accumulates more than twofold in upf1s, nmd2s, and upf3s cells. Those studies also showed that the transcript for the closely related Alr2 protein-which, if overexpressed, improves growth of alr1 $\Delta$ cells (MacDiarmid and Gardner 1998/_accumulates in upf1s, nmd2s, and upf3s cells, and is rapidly degraded upon NMD reactivation. Decay rate measurements revealed that the increased abundance of $A L R 1$ and ALR2 mRNAs in upf1A cells correlates to an increase in their half-lives (Fig. 2A,B), demonstrating that they are bona fide substrates of the NMD pathway. These findings implied that the reduced termination fidelity of NMD-deficient cells may be caused by increased Alr1p and Alr2p expression, and the consequent effects of elevated $\mathrm{Mg}^{2+}$ levels. Figure 2, C-E, demonstrates that Alr1p and Alr2p do accumulate in upf1s cells, correlating with an increase in free cellular $\mathrm{Mg}^{2+}$. The finding that NMD down-regulates not only expression of Alr1p, but also that of Alr2p, explained: (1) the partial suppression of the growth defect of an alr1s mutant by upf $1 \Delta, n m d 2 \Delta$, or upf3 $\Delta$ alleles; (2) the slightly higher readthrough levels in upf1s alr1s cells versus
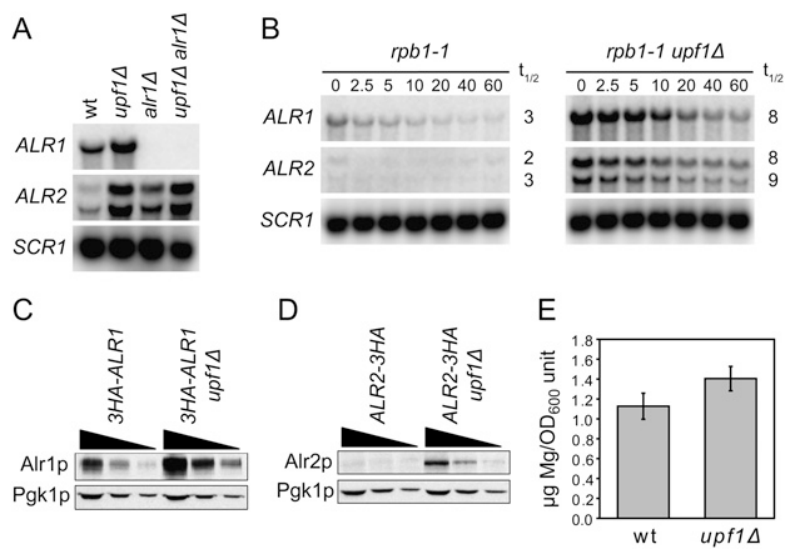

Figure 2. NMD-deficient cells show increased expression of magnesium transporters. (A) Northern analysis of total RNA isolated from wild-type (MJY142), upf1s (MJY67), alr1s (MJY130), and upf1s alr1s (MJY447) cells grown in SC medium at $30^{\circ} \mathrm{C}$. The blot was probed for $A L R 1, A L R 2$, and SCR1 transcripts using randomly labeled DNA fragments. (B) mRNA decay rates in $r p b 1-1$ (MJY249) and $r p b 1-1$ upf1s (MJY251) cells. The strains were grown at $24^{\circ} \mathrm{C}$ in SC medium followed by inhibition of RNA polymerase II transcription by a shift to $37^{\circ} \mathrm{C}$. Time points (minutes) after the shift are indicated above the lanes. The signal in each lane was normalized to the corresponding SCR 1 signal, and the half-life $\left(t_{1 / 2}\right.$, in minutes) was determined from the initial slope of the curve. $(C, D)$ Western blot analyses of twofold serial dilutions of cell extracts from strains in which the DNA sequence for three tandem influenza virus hemagglutinin epitopes (3HA) was fused to the endogenous ALR1 $(C$, MJY290 and MJY309) or $A L R 2$ (D, MJY167 and MJY183) ORF. Monoclonal antibodies against HA or Pgklp were used to detect the indicated proteins. Control experiments showed that the sequence for the 3HA tag did not prevent accumulation of the transcripts in upf1s cells (Supplemental Fig. S2). (E) $\mathrm{Mg}^{2+}$ levels in supernatants of permeabilized wild-type (MJY142) and upf1s (MJY67) cells. The values, determined by using eriochrome blue SE, represent the average from four independent cultures of each strain. The standard deviation is indicated. A two-tailed Student's $t$-test revealed that the value for the upf1s strain is significantly different from that of the wild type $(P=0.02)$. 
alr1s cells; and (3) the elimination of the suppressing

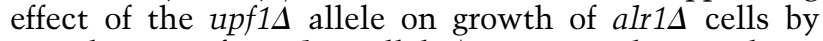
introduction of an alr2s allele (Fig. 1; Supplemental Fig. S3; data not shown). Consistent with the notion that Alr2p plays a minor role in $\mathrm{Mg}^{2+}$ uptake (MacDiarmid and Gardner 1998; Wachek et al. 2006), an alr2s allele does not counteract the nonsense suppression phenotype of upf1s cells or prevent accumulation of $\mathrm{Mg}^{2+}$ in the presence of elevated Alrlp levels (data not shown; see below). Collectively, these results suggest a model in which the readthrough phenotype of NMD-deficient cells is caused by elevated $\mathrm{Mg}^{2+}$ levels, primarily through increased Alr1p expression, and their effects on translational fidelity.

\section{Alr1p levels modulate the fidelity of translation termination}

If elevated $\mathrm{Mg}^{2+}$ levels are the basis of increased readthrough in NMD-deficient cells, then the phenotype should be abolished by restoring normal Alr1p expression levels. Furthermore, wild-type cells with increased expression of Alrlp should show elevated levels of readthrough. To test these predictions, we constructed wildtype and upf1s cells in which the sequence upstream of the chromosomal $3 H A-A L R 1$ ORF was replaced with the promoter and $5^{\prime}$-untranslated region $\left(5^{\prime}\right.$-UTR) of the regulatable MET3 gene (Mao et al. 2002). To exclude the possibility that differences in Alr2p expression would influence the results, we also introduced an alr2 $\Delta$ allele into the strains. The $3 H A-A L R 1$ transcript harboring the MET3 5'-UTR is largely resistant to NMD, although the level of the transcript was consistently somewhat higher in upf1s cells (Supplemental Fig. S4; Supplemental Table S2). By titrating the methionine concentration in the medium, we found that the presence of $300 \mu \mathrm{M}$ methionine generated Alrlp and $\mathrm{Mg}^{2+}$ levels comparable with those observed in the control 3HA-ALR1 alr2A strain (Fig. $3 \mathrm{~A}, \mathrm{~B})$. The methionine concentration required to mimic the Alr1p levels in the $3 H A-A L R 1$ alr2 2 upf1 $1 \Delta$ strain was too low for reproducible analyses of the readthrough levels; i.e., slight differences in the number of cell divisions yielded large variations in the Alrlp levels. We therefore analyzed the strains with full derepression of $P_{\text {MET3 }}$ with the caveat that this generates Alr1p levels that are considerably higher than those observed in the 3HA-ALR1 alr2A upf1S strain (Fig. 3A). Consistent with the somewhat higher abundance of the MET3 5'-UTRcontaining $3 H A-A L R 1$ transcript in upf1s cells, the derepression of $P_{M E T 3}-3 H A-A L R 1$ yielded slightly higher Alrlp and $\mathrm{Mg}^{2+}$ levels in the upf1s derivative (Fig. 3A,B; data not shown). As predicted, the efficiency of translation termination correlated inversely with $\mathrm{Mg}^{2+}$ levels; i.e., the readthrough phenotype of upf1s cells was abolished by restoring normal Alr1p expression levels, and elevated Alrlp expression induced readthrough even in NMD-proficient cells (Fig. 3C). The relative abundance of the can1-100 and leu2-2 nonsense transcripts was unaffected by Alrlp levels irrespective of the NMD status of the cells (Supplemental Fig. S4A; Supplemental Table S2), indicating that the accumulation of nonsense transcripts in upf1s cells is unrelated to the Alrlp expression level, and that NMD occurs independently of its effects on $\mathrm{Mg}^{2+}$ uptake. Collectively, these results show that $\mathrm{Mg}^{2+}$ levels modulate the efficiency of termination in vivo, and they strongly support the notion that the reduced termi-
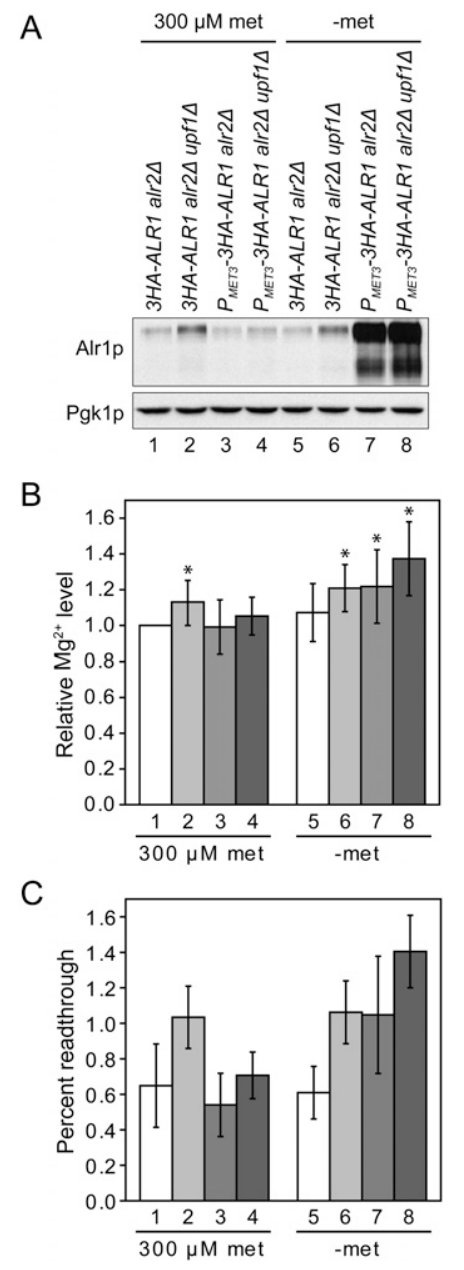

Figure 3. Increased Alrlp expression accounts for the reduced termination fidelity of NMD-deficient cells. (A) Western blot analysis of the 3HA-ALR1 alr2A (MJY455), 3HA-ALR1 alr2A upf1S (MJY456), $P_{\text {MET3-3HA-ALR1 alr2S (MJY430), and } P_{M E T 3}-3 H A-A L R 1}$ alr2s upf1s (MJY432) strains. The strains were grown in SC-cys medium containing $300 \mu \mathrm{M}$ met, harvested and washed with water, diluted to $\mathrm{OD}_{600} \sim 0.1$ in fresh SC-cys (300 $\mu \mathrm{M}$ met) and SC-met-cys medium, and allowed to grow for two generations. Monoclonal antibodies against HA or Pgklp were used to detect the indicated proteins. (B) $\mathrm{Mg}^{2+}$ levels in selected strains. Cells were grown as described above and assessed for $\mathrm{Mg}^{2+}$ levels by using eriochrome blue SE, and the resulting values were expressed relative to that obtained for the $3 H A-A L R 1$ alr2A strain (300 $\mu \mathrm{M}$ met), which was set to 1 . Strains are numbered as in $A$. The values represent the average of 10 independent experiments. The standard deviation is indicated. An asterisk indicates that the value is significantly different from 1 using the Wilcoxon signed rank test $(P<0.05) .(C)$ Readthrough of the UAA codon in strains shifted to medium with or without $300 \mu \mathrm{M}$ met. Cells were manipulated as in $A$, except that the medium also lacked uracil to allow selection for the reporter plasmids. Strains are numbered as in $A$. The values represent the average of five independent experiments. The standard deviation is indicated.

nation fidelity of NMD-deficient yeast cells is an indirect consequence of increased Alrlp expression. While our findings do not contradict the notion that NMD may be triggered by the intrinsic inefficiency of premature termination (Amrani et al. 2004), they suggest that the detection of altered termination fidelity in NMD-deficient cells is a reflection of the set of endogenous 
transcripts subject to NMD regulation. Since the sets of endogenous NMD substrates differ in yeast and metazoans (Rehwinkel et al. 2006), this also explains why down-regulation of NMD in mammalian cells can lead to unchanged or even reduced levels of translational readthrough (Mendell et al. 2002; Ivanov et al. 2008).

\section{$N M D$ regulation of $A l r 1 p$ levels requires an upstream ORF (uORF) in the ALR1 5'-UTR}

The observation that the MET3 5'-UTR-containing ALR1 transcript is largely resistant to NMD (Supplemental Fig. S4B) suggested that the ALR1 5'-UTR may be responsible for triggering decay. To assess this possibility, we replaced the sequences upstream of the endogenous LYS2 ORF with the promoter and $5^{\prime}$-UTR of the ALR1 gene. Introduction of a upf1s allele into cells harboring this $P_{A L R 1-L Y S 2}$ allele improved growth on medium lacking lysine, which correlated with increased levels of ALR15'-UTR-LYS2 transcripts (Fig. 4A,B). Determination of $A L R 1$ 5'-UTR lengths and subsequent mutational analyses of upstream AUG codons revealed that the NMD reactivity of $A L R 1$ transcripts is caused by the inclusion of one to three uORFs (Fig. 4C; Supplemental Material; Supplemental Fig. S5). Although these analyses showed that alternative extended transcripts encompassing $\mathrm{UORF} 1$ and $\mathrm{uORF} 2 \mathrm{~A} / 2 \mathrm{~B}$ contributed to the pool of NMD-regulated $A L R 1$ transcripts, they also suggested that the shorter uORF3-containing transcripts accounted for the NMD-dependent regulation of Alrlp levels (Fig. 4D). This notion was supported further by the finding
A

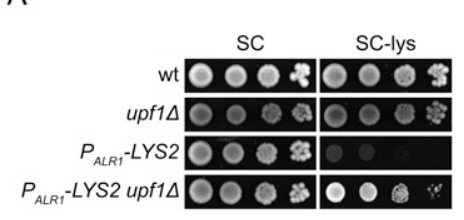

C

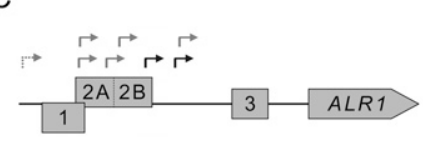

B

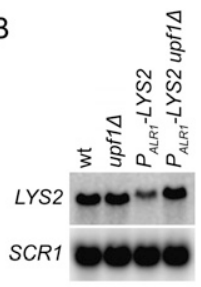

D

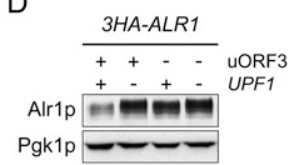

Figure 4. NMD-regulation of Alrlp levels is attributable to a uORF in the ALR1 5'-UTR. (A) Growth in the absence of lysine. The indicated strains (MJY142, MJY67, MJY363, and MJY365) were grown overnight in SC medium at $30^{\circ} \mathrm{C}$, serially diluted, spotted onto SC and SC-lys plates, and incubated for $3 \mathrm{~d}$ at $30^{\circ} \mathrm{C}$. $(B)$ Northern analysis of total RNA isolated from indicated strains (MJY142, MJY67, MJY363, and MJY365) grown in SC medium at $30^{\circ} \mathrm{C}$. The blot was probed for LYS2 and SCR1 transcripts using randomly labeled DNA fragments. $(C)$ The chromosomal region upstream of the ALR1 ORF. uORF1, uORF2A/2B, and uORF3 are shown as boxes. Transcriptional start sites, as determined by $5^{\prime}$ RLM-RACE, are indicated with gray arrows (identified in upf14 [MJY67] cells) and black arrows (identified in both wild-type [MJY142] and upf1s cells). The dashed arrow indicates the presence of an extended subspecies encompassing uORF1 and uORF2A (see the Supplemental Material). (D) Western analysis of the indicated strains (MJY290, MJY309, MJY422, and MJY424) grown in SC medium at $30^{\circ} \mathrm{C}$. uORF3 was eliminated by changing the sequence for the AUG codon to AAG. Monoclonal antibodies against HA or Pgklp were used to detect the indicated proteins. that uORF3-dependent NMD regulation of $A L R 1$ mRNA and Alr1p levels was largely intact in cells in which the $5^{\prime}$-UTR sequence upstream of uORF3 had been replaced with the $5^{\prime}$-UTR sequence of the MET3 transcript (Supplemental Fig. S6).

\section{Concluding remarks}

The importance of $\mathrm{Mg}^{2+}$ as a cofactor/counterion and its role in establishing and maintaining structures of nucleic acids, proteins, and membranes implies that cells must strictly control intracellular $\mathrm{Mg}^{2+}$ concentrations. It was shown previously that expression of $S$. cerevisiae Alrlp is regulated at the levels of protein stability and mRNA abundance (Graschopf et al. 2001), and our results demonstrate that $A L R 1$ (and $A L R 2$ ) mRNA levels are at least partially controlled by the NMD pathway. Since uORF3 is conserved in other Saccharomyces species (Cvijovic et al. 2007), NMD regulation of $\mathrm{Mg}^{2+}$ uptake and translational fidelity may be a widespread phenomenon. However, it remains to be seen whether altered $\mathrm{Mg}^{2+}$ levels contribute to other phenotypes reported for NMD-deficient yeast cells.

Elevated $\mathrm{Mg}^{2+}$ levels have been shown previously to decrease translational fidelity in cell-free systems (Szer and Ochoa 1964; Capecchi 1967; Schlanger and Friedman 1973), but, to the best of our knowledge, comparable effects have not been demonstrated in vivo. Given the importance of $\mathrm{Mg}^{2+}$ ions to ribosome structure (Selmer et al. 2006), one possible mechanism for $\mathrm{Mg}^{2+}$-mediated mistranslation would involve a conformational distortion of the A site that, much like aminoglycoside-induced nonsense suppression, would falsely trigger flipping of bases that normally monitor mRNA:tRNA base-pairing (Vicens and Westhof 2003).

\section{Materials and methods}

Strains, plasmids, media, and genetic procedures

Yeast strains used in this study are listed in Supplemental Table S3. Yeast transformations, media, and genetic procedures have been described (Amberg et al. 2005). Unless stated otherwise, all experiments were performed using exponentially growing cells at an optical density at 600 $\mathrm{nm}\left(\mathrm{OD}_{600}\right)$ of $\sim 0.5$. Standard methods (Longtine et al. 1998; Tong et al. 2001; Amberg et al. 2005) were used to delete genes and to integrate sequences for markers, promoters, tags, and mutant alleles. Deletions of genes and integration of markers were confirmed by PCR using primers that annealed outside of sequences present in the transformed DNA fragment(s). Integrations of promoters, tags, and mutant alleles were confirmed by DNA sequencing of the relevant PCR products. The genetic screen and details of strain and plasmid constructions are described in the Supplemental Material.

\section{RNA methods}

mRNA levels and mRNA half-lives were determined essentially as described previously (Johansson et al. 2007; He et al. 2008). Transcriptional start sites were mapped by using the FirstChoice RLM-RACE kit (Ambion) combined with the TOPO TA Cloning Kit for Sequencing (Invitrogen), and subsequent DNA sequencing of seven to 10 clones for each strain.

\section{Cell extracts and Western blotting procedures}

Cells representing four $\mathrm{OD}_{600}$ units were harvested, washed once with water, and resuspended in $200 \mu \mathrm{L}$ of a slightly modified version of a previously described sample buffer $(8.75 \mathrm{mM}$ Tris- $\mathrm{HCl}$ at $\mathrm{pH} 6.8,8 \mathrm{M}$ urea, $0.875 \%$ sodium dodecyl sulfate [SDS], $1 \% \quad \beta$-mercaptoethanol, 
$1 \times$ protease inhibitor cocktail [Roche Applied Science], bromphenol blue) (Schandel and Jenness 1994). Samples were transferred to 2-mL tubes containing $\sim 0.15 \mathrm{~g}$ of glass beads $(425-600 \mu \mathrm{m}$, Sigma-Aldrich), vortexed six times for $30 \mathrm{sec}$ with $1 \mathrm{~min}$ on ice between steps, and incubated for 10 min at $37^{\circ} \mathrm{C}$. Following centrifugation, a fraction of the samples, typically $10 \mu \mathrm{L}$, was resolved by $8 \%$ SDS-PAGE, transferred to Immobilon-P (Millipore) membranes, and incubated with monoclonal anti-HA antibodies (12CA5, Roche Applied Science) and then with horseradish peroxidase-conjugated goat anti-mouse IgG (Zymed laboratories). Blots were stripped and reprobed with monoclonal anti-Pgklp antibodies (22C5D8, Molecular Probes). Proteins were detected using ECL Western blotting detection reagents (GE Healthcare) and Kodak BioMax light film.

\section{Dual-luciferase assays}

Readthrough assays were performed using the dual-luciferase reporter assay system (Promega) and a TD-20/20 luminometer (Turner Biosystems). An appropriate number of cells in $5 \mu \mathrm{L}$ of the relevant medium was transferred to $100 \mu \mathrm{L}$ of passive lysis buffer followed by $12 \mathrm{sec}$ of vortexing and immediate use of $20 \mu \mathrm{L}$ of lysate for the assay. When performing readthrough assays in $\left[\mathrm{psi}^{-}\right]$strains, the firefly and Renilla activities were determined using different numbers of cells, ensuring that the values were within the linear range of the respective assay. Each individual culture was assayed three times, and the values were derived from five independent experiments, performed on different days, using independent transformants for each experiment.

\section{Magnesium measurements}

Cells representing $\sim 15 \mathrm{OD}_{600}$ units were harvested and washed once with water and twice with buffer $\mathrm{E}$ (30 mM MOPS at pH 7.1, $100 \mathrm{mM} \mathrm{KCl),} \mathrm{and}$ aliquots from the last wash step were used for a final $\mathrm{OD}_{600}$ reading. Following centrifugation of a defined volume of the remaining sample, the cell pellet was resuspended in buffer ET (bufffer E containing 0.05\% Triton $\mathrm{X}-100)$, frozen on dry ice, and stored at $-70^{\circ} \mathrm{C}$. The frozen cell suspension was transferred for $30 \mathrm{~min}$ to $30^{\circ} \mathrm{C}$, vortexed briefly, and centrifuged for $5 \mathrm{~min}$. The supernatants were transferred to fresh $1.5-\mathrm{mL}$ tubes, and the $\mathrm{Mg}^{2+}$ concentration was determined using eriochrome blue SE essentially as described previously (Scarpa 1974). Briefly, the $\mathrm{Mg}^{2+}$ levels were determined in buffer E containing $30 \mu \mathrm{M}$ eriochrome blue SE (SigmaAldrich) by measuring the difference in absorbance at 592 and $554 \mathrm{~nm}$. A standard curve was obtained using dilutions of an $\mathrm{MgCl}_{2}$ stock solution. Each sample was assayed three times, and the magnesium concentration was calculated per $\mathrm{OD}_{600}$ unit. Mock samples consisting of the same volume of medium as the cultures were subjected to all steps of the protocol to ensure that the background was negligible.

\section{Acknowledgments}

We thank A. Byström and D. Bedwell for strains and plasmids. P. Rydén and members of A.J.'s laboratory are acknowledged for helpful comments on the manuscript. This work was supported by a grant to A.J. from the National Institutes of Health. During his stay in A.J.'s laboratory, M.J.O.J. was supported in part by a post-doctoral fellowship from the Swedish Research Council.

\section{References}

Amberg DC, Burke DI, Strathern JN. 2005. Methods in yeast genetics. Cold Spring Harbor Laboratory Press, Cold Spring Harbor, NY.

Amrani N, Ganesan R, Kervestin S, Mangus DA, Ghosh S, Jacobson A. 2004. A faux 3'-UTR promotes aberrant termination and triggers nonsense-mediated mRNA decay. Nature 432: 112-118.

Capecchi MR. 1967. Polarity in vitro. J Mol Biol 30: 213-217.

Cvijovic M, Dalevi D, Bilsland E, Kemp GJ, Sunnerhagen P. 2007. Identification of putative regulatory upstream ORFs in the yeast genome using heuristics and evolutionary conservation. BMC Bioinformatics 8: 295. doi: 10.1186/1471-2105-8-295.

Czaplinski K, Ruiz-Echevarria MJ, Paushkin SV, Han X, Weng Y, Perlick HA, Dietz HC, Ter-Avanesyan MD, Peltz SW. 1998. The surveillance complex interacts with the translation release factors to enhance termination and degrade aberrant mRNAs. Genes Dev 12: 1665-1677.
Graschopf A, Stadler JA, Hoellerer MK, Eder S, Sieghardt M, Kohlwein SD, Schweyen RJ. 2001. The yeast plasma membrane protein Alr1 controls $\mathrm{Mg}^{2+}$ homeostasis and is subject to $\mathrm{Mg}^{2+}$-dependent control of its synthesis and degradation. J Biol Chem 276: 16216-16222.

He F, Li X, Spatrick P, Casillo R, Dong S, Jacobson A. 2003. Genome-wide analysis of mRNAs regulated by the nonsense-mediated and $5^{\prime}$ to $3^{\prime}$ mRNA decay pathways in yeast. Mol Cell 12: 1439-1452.

He F, Amrani N, Johansson MJO, Jacobson A. 2008. Qualitative and quantitative assessment of the activity of the yeast nonsense-mediated mRNA decay pathway. Methods Enzymol 449: 127-147.

Ivanov PV, Gehring NH, Kunz JB, Hentze MW, Kulozik AE. 2008. Interactions between UPF1, eRFs, PABP and the exon junction complex suggest an integrated model for mammalian NMD pathways. EMBO I 27: 736-747.

Jacobson A, Izaurralde E. 2007. Nonsense-mediated mRNA decay: From yeast to metazoans. In Translational control in biology and medicine (ed. MB Mathews et al.), pp. 655-688. Cold Spring Harbor Laboratory Press, Cold Spring Harbor, NY.

Johansson MJO, He F, Spatrick P, Li C, Jacobson A. 2007. Association of yeast Upflp with direct substrates of the NMD pathway. Proc Natl Acad Sci 104: 20872-20877.

Keeling KM, Lanier J, Du M, Salas-Marco J, Gao L, Kaenjak-Angeletti A, Bedwell DM. 2004. Leaky termination at premature stop codons antagonizes nonsense-mediated mRNA decay in S. cerevisiae. RNA 10: 691-703.

Longtine MS, McKenzie A 3rd, Demarini DJ, Shah NG, Wach A, Brachat A, Philippsen P, Pringle JR. 1998. Additional modules for versatile and economical PCR-based gene deletion and modification in Saccharomyces cerevisiae. Yeast 14: 953-961.

MacDiarmid CW, Gardner RC. 1998. Overexpression of the Saccharomyces cerevisiae magnesium transport system confers resistance to aluminum ion. J Biol Chem 273: 1727-1732.

Maderazo AB, He F, Mangus DA, Jacobson A. 2000. Upflp control of nonsense mRNA translation is regulated by Nmd2p and Upf3p. Mol Cell Biol 20: 4591-4603.

Mao X, Hu Y, Liang C, Lu C. 2002. MET3 promoter: A tightly regulated promoter and its application in construction of conditional lethal strain. Curr Microbiol 45: 37-40.

Mendell JT, ap Rhys CM, Dietz HC. 2002. Separable roles for rent1/hUpfl in altered splicing and decay of nonsense transcripts. Science 298: 419-422.

Rehwinkel J, Raes J, Izaurralde E. 2006. Nonsense-mediated mRNA decay: Target genes and functional diversification of effectors. Trends Biochem Sci 31: 639-646.

Scarpa A. 1974. Indicators of free magnesium in biological systems. Biochemistry 13: 2789-2794.

Schandel KA, Jenness DD. 1994. Direct evidence for ligand-induced internalization of the yeast $\alpha$-factor pheromone receptor. Mol Cell Biol 14: 7245-7255.

Schlanger G, Friedman SM. 1973. Ambiguity in a polypeptide-synthesizing extract from Saccharomyces cerevisiae. J Bacteriol 115: 129-138.

Selmer M, Dunham CM, Murphy FV, Weixlbaumer A, Petry S, Kelley AC, Weir JR, Ramakrishnan V. 2006. Structure of the 70 S ribosome complexed with mRNA and tRNA. Science 313: 1935-1942.

Szer W, Ochoa S. 1964. Complexing ability and coding properties of synthetic polynucleotides. J Mol Biol 8: 823-834.

Tong AH, Evangelista M, Parsons AB, Xu H, Bader GD, Page N, Robinson M, Raghibizadeh S, Hogue CW, Bussey H, et al. 2001. Systematic genetic analysis with ordered arrays of yeast deletion mutants. Science 294: 2364-2368.

Tuite MF, Mundy CR, Cox BS. 1981. Agents that cause a high frequency of genetic change from $\left[\mathrm{psi}^{+}\right]$to $\left[\mathrm{psi}^{-}\right]$in Saccharomyces cerevisiae. Genetics 98: 691-711.

Vicens Q, Westhof E. 2003. RNA as a drug target: The case of aminoglycosides. Chembiochem 4: 1018-1023.

Wachek M, Aichinger MC, Stadler JA, Schweyen RJ, Graschopf A. 2006. Oligomerization of the $\mathrm{Mg}^{2+}$-transport proteins Alr1p and Alr2p in yeast plasma membrane. FEBS T 273: 4236-4249.

Wang W, Czaplinski K, Rao Y, Peltz SW. 2001. The role of Upf proteins in modulating the translation read-through of nonsense-containing transcripts. EMBO J 20: 880-890.

Weng Y, Czaplinski K, Peltz SW. 1996. Genetic and biochemical characterization of mutations in the ATPase and helicase regions of the Upf1 protein. Mol Cell Biol 16: 5477-5490. 


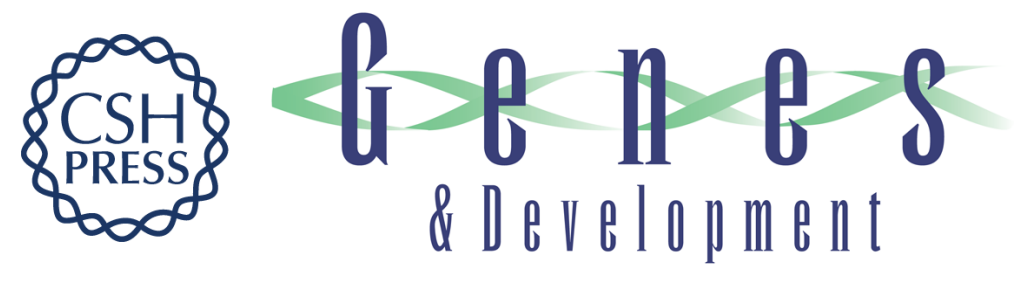

\section{Nonsense-mediated mRNA decay maintains translational fidelity by limiting magnesium uptake}

Marcus J.O. Johansson and Allan Jacobson

Genes Dev. 2010, 24:

Access the most recent version at doi:10.1101/gad.1930710

Supplemental http://genesdev.cshlp.org/content/suppl/2010/07/12/24.14.1491.DC1
Material

References This article cites 27 articles, 13 of which can be accessed free at:

http://genesdev.cshlp.org/content/24/14/1491.full.html\#ref-list-1

License

Email Alerting

Receive free email alerts when new articles cite this article - sign up in the box at the top

Service

right corner of the article or click here.

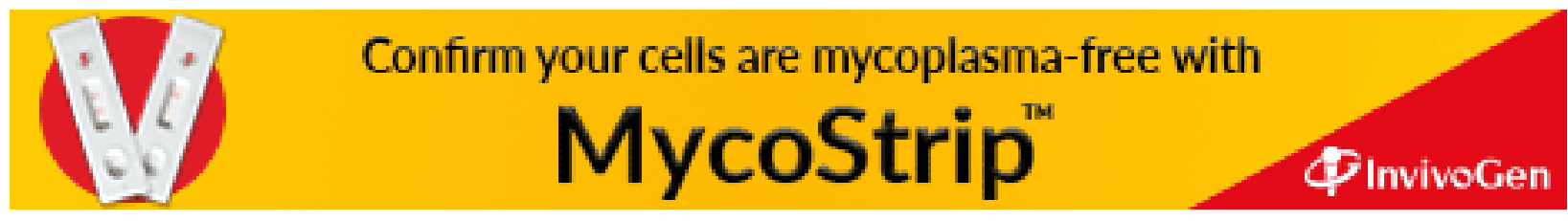

